\title{
Mineralocorticoid concentrations in unstressed female rabbits and embryonic sodium transport
}

\author{
L. L. Nielsen*, D. J. Benos† and J. D. Biggers \\ Department of Physiology \& Biophysics and Laboratory of Human Reproduction and Reproductive \\ Biology (LHRRB), Harvard Medical School, 45 Shattuck St., Boston, MA 02115, U.S.A.
}

\begin{abstract}
Summary. Plasma aldosterone, corticosterone, and cortisol were measured during the first week of pseudopregnancy or pregnancy in New Zealand White rabbits to determine whether any sustained elevations of adrenal steroids occur. There were no pregnancyspecific alterations in circulating adrenal steroid concentrations during the preimplantation stages of embryonic development. Elevation of plasma aldosterone in vivo did not induce amiloride-sensitive $\mathrm{Na}^{+}$transport across the embryonic trophectoderm. It therefore seems unlikely that an increase in maternal adrenal steroid concentrations is necessary for the development of amiloride-sensitive $\mathrm{Na}^{+}$transport in rabbit blastocysts.

Sodium efflux from Day 6 post coitum (p.c.) blastocysts was lower than $\mathrm{Na}^{+}$influx. By day 7 p.c. $\mathrm{Na}^{+}$efflux was equivalent in magnitude to the component of $\mathrm{Na}^{+}$influx not inhibited by amiloride. This suggests that between Days 6 and 7 p.c. the amiloridesensitive component of $\mathrm{Na}^{+}$influx becomes essential for blastocyst expansion.
\end{abstract}

\section{Introduction}

The rabbit blastocyst undergoes a dramatic size increase before implantation. Blastocoele volume increases from $2 \mathrm{nl}$ on Day 3 post coitum (p.c.) to about $70 \mu \mathrm{l}$ on Day 7 p.c. (Daniel, 1964; Nielsen, 1986). This fluid accumulation is dependent upon active $\mathrm{Na}^{+}$influx across the trophectoderm of the blastocyst (Borland et al., 1976). By Day 6 p.c. as much as $30 \%$ of this flux is inhibited in vitro by the diuretic drug amiloride in concentrations of $0 \cdot 1-1.0 \mathrm{mM}$ (L. L. Nielsen, unpublished observation), while as much as $70 \%$ is inhibited by the same amiloride concentrations on Day 7 p.c. (Benos, 1981). Powers et al. (1977) demonstrated that, between Days 6 and 7 p.c., the transtrophectodermal potential difference undergoes a dramatic increase from approximately $-3 \mathrm{mV}$ on Day 6 p.c. to $+21 \mathrm{mV}$ on Day 7 p.c., the external bath being at ground potential. Administration of $10 \mu \mathrm{M}-$ amiloride or removal of external $\mathrm{Na}^{+}$reduced the potential difference to $-3 \mathrm{mV}$ in the older embryos. This suggests that a conductive $\mathrm{Na}^{+}$transport system is activated between Days 6 and 7 p.c.

The steroid hormone aldosterone increases conductive, amiloride-sensitive $\mathrm{Na}^{+}$transport in adult rat colon (Will et al., 1980, 1985; Perrone et al., 1984; Perrone \& Jenks, 1984; Bridges et al., 1987), neonatal pig colon (Ferguson et al., 1979; Cremaschi et al., 1979), toad urinary bladder (MacKnight et al., 1980; Palmer \& Edelman, 1981), and frog skin (Crabbe, 1964). In all these tissues, aldosterone induces a conductive transport pathway due to the activation of an amiloridesensitive $\mathrm{Na}^{+}$channel in the apical membranes of the epithelia. Therefore, because there is an

*Present address: Laboratory of Radiobiology \& Environmental Health, University of California, San Francisco, CA 94122 , U.S.A.

$\uparrow$ Present address: Department of Physiology \& Biophysics, University of Alabama at Birmingham, University Station, Birmingham, AL 35294, U.S.A. 
amiloride-sensitive potential difference across the rabbit trophectoderm, it seemed likely that aldosterone induced the amiloride-sensitive component of $\mathrm{Na}^{+}$influx between Days 6 and 7 p.c.

We therefore investigated whether plasma mineralocorticoid concentrations rise during the preimplantation stage of pregnancy and whether supraphysiological aldosterone concentrations in vivo have any stimulatory effect on embryonic amiloride-sensitive $\mathrm{Na}^{+}$influx measured in vitro. In addition, the rate of $\mathrm{Na}^{+}$efflux from the blastocoele was measured to examine the contribution of the amiloride-sensitive $\mathrm{Na}^{+}$influx to blastocyst expansion.

\section{Materials and Methods}

Rabbit catheters. Virgin female New Zealand White rabbits aged 6-10 months were each given an injection $(0 \cdot 9 \mathrm{mg} / \mathrm{kg}$ body wt) of promazine $\mathrm{HCl}$ (Sparine: Wyeth Laboratories, Philadelphia, PA) $\mathrm{l}-2 \mathrm{~h}$ before surgery. A $2 \%$ solution of thiamylal sodium (Bio-tal: Bio-Ceutic Laboratories, Inc., St. Joseph, MI) was administered as needed via the marginal ear vein to maintain anaesthesia during surgery. Sterile surgical techniques were used to implant catheters (Tygon microbore tubing, Norton Co., Akron, $\mathrm{OH}$ ) into the superior vena cava and to exteriorize them in the dorsal neck region. Blood samples were collected into heparinized tubes via the catheters. This method of blood collection avoided the high stress imposed on animals by most sampling procedures (i.e. venesection, cardiac puncture). Plasma was collected and frozen at $-80^{\circ} \mathrm{C}$ and the red blood cells were reinjected into each rabbit via its catheter. Haematocrits did not change during the course of the experiment and averaged $30 \pm 1 \%$ ( \pm s.d.; 9 samples/rabbit for 11 rabbits). Between samples the catheters were filled with heparin $(670 \mathrm{i} . \mathrm{u} . / \mathrm{ml} 0.9 \%(\mathrm{w} / \mathrm{v}) \mathrm{NaCl})$ and plugged. All animals were maintained on a $14 \mathrm{~h}$ light/10 h dark cycle starting at $05: 00 \mathrm{~h}$. At 10:00 h on Day 0, rabbits were either naturally mated to two bucks or injected with 25 i.u. human chorionic gonadotrophin (hCG) to induce ovulation.

Radioimmunoassay ( $R I A$ ). Radioimmunoassays were developed for the measurement of plasma progesterone, aldosterone, corticosterone and cortisol concentrations. All solvents were reagent grade or nanograde, purchased from Mallinckrodt, Inc. (Paris, KY). All ${ }^{3} \mathrm{H}$-labelled steroids and non-radioactive steroids were purchased from New England Nuclear (Boston, MA) and Sigma Chem. Co. (St Louis, MO), respectively. Plasma steroids plus ${ }^{3} \mathrm{H}$-labelled steroid tracers ( 1000 c.p.m. per steroid) were extracted from plasma into 7 volumes of dichloromethane. After centrifugation at $600 \mathrm{~g}$ and $4^{\circ} \mathrm{C}$ for $15 \mathrm{~min}$, the aqueous layer was frozen on the sides of the test tubes by using a solid $\mathrm{CO}_{2}$-methane bath. The organic layer was decanted and dried in vacuo. The dried steroids were then dissolved in absolute ethanol and stored at $-20^{\circ} \mathrm{C}$ overnight. Steroids were separated on celite microcolumns using the method of Manlimos \& Abraham (1975) with modifications. Briefly, the extracted steroids were dried under nitrogen gas, redissolved in $1 \mathrm{ml} 20 \%$ ethyl acetate in trimethylpentane saturated with ethylene glycol:water $(80 / 20, \mathrm{v} / \mathrm{v})$ and then chromatographed on celite (J. T. Baker Chem. Co., Phillipsburg, NJ) microcolumns impregnated with $20 \%$ water in ethylene glycol. Nitrogen gas was applied to the tops of the columns to ensure uniform flow rates of $0.2-0.3 \mathrm{ml} / \mathrm{min}$. The fractional separation was performed as shown in Table 1. The collected fractions were dried, then dissolved in $0.1 \% \mathrm{Knox}$ gelatin in $0.1 \mathrm{M}$-phosphate-buffered saline, $\mathrm{pH} 7.0$ (PBS-gel buffer). Small aliquants were taken from each sample and counted in $4 \mathrm{ml}$ Ready-Solv HP (Beckman) in a Tracor Analytic 6895 liquid scintillation spectrometer for determination of procedural losses. The RIA tubes were set up such that each tube contained $100 \mu 1$ antibody, $100 \mu l$ ${ }^{3} \mathrm{H}$-labelled steroid, and a total of $400 \mu \mathrm{l}$ sample plus PBS-gel buffer. After overnight equilibration of the steroidreceptor complexes at $4^{\circ} \mathrm{C}$, the assay tubes were incubated for $10 \mathrm{~min}$ with Dextran T-70-coated charcoal, centrifuged for $10 \mathrm{~min}$ at $3000 \mathrm{~g}$, and decanted into $4 \mathrm{ml}$ Ready-Solv HP for determination of bound radioactivity. Doses and standard curves were computed using the program RIA001 (Rodbard \& Rodgers, 1976).

Cross-reactivity of the progesterone antibody (GDN-337 (Gibori et al., 1977) was less than $0.001 \%$ with cortisol, aldosterone, oestradiol- $17 \beta$, or testosterone; $1.5 \%$ with corticosterone; $1.9 \%$ with 11 -deoxycorticosterone; $2.3 \%$ with oestrone; $3.8 \%$ with pregnenolone; $6.0 \%$ with 17 -hydroxyprogesterone; and $19.6 \%$ with 11 -deoxycortisol. Crossreactivity of the aldosterone antibody (Underwood \& Williams, 1972) was less than $0.001 \%$ with progesterone, corticosterone, cortisol, oestradiol-17 $\beta$, pregnenolone, androstenedione, testosterone, $5 \alpha$-dihydrotestosterone (DHT), or dehydroepiandrosterone sulphate, and $0.41 \%$ with 11 -deoxycortisol. Cross-reactivity of the corticosterone antibody (Radioassay Systems Lab., Inc., Carson, CA) was less than 0.001\% with oestradiol-17 $\beta$, oestriol, testosterone, oestrone, or 11-deoxycortisol; $0.04 \%$ with dehydroepiandrosterone (DHA); $0.89 \%$ with aldosterone; $3.5 \%$ with DHT; $4.9 \%$ with pregnenolone; $31.4 \%$ with cortisol; $52.6 \%$ with progesterone; and $54.9 \%$ with 17 -hydroxyprogesterone. Crossreactivity of the cortisol antibody 21 (raised in the LHRRB by R. Todd) was less than $0.001 \%$ with progesterone, aldosterone, 17-hydroxyprogesterone, 11-deoxycortisol, DHA, pregnenolone, oestradiol-17 $\beta$, oestrone, androstenedione, or DHT; $0.03 \%$ with testosterone; and $4.1 \%$ with corticosterone. Intra-assay variabilities were $5.9 \%, 19.7 \%$, $6.5 \%$ and $13.6 \%$ for progesterone, aldosterone, corticosterone and cortisol assays, respectively. Interassay variabilities were $16.0 \%, 17.5 \%, 14.3 \%$ and $21.2 \%$ for the same steroids. No steroids were detected in water blanks routinely processed as samples in any of the assays. Known quantities of the three corticosteroids were added to rabbit plasma pools, then processed in the same manner as normal samples to determine assay accuracy. Five different doses of each steroid were used such that the accuracy of sample measurements across the entire range of the dose-response curves was checked. The mean percentage variation of the measured steroids from the theoretical values was 11.0 for aldosterone, 11.5 for corticosterone, and $15 \cdot 1$ for cortisol. 
Table 1. Chromatographic separation of steroids

\begin{tabular}{cccc}
\hline Fraction & Volume $(\mathrm{ml})$ & Mobile phase* & Steroid \\
\hline Void & $1 \cdot 0$ & $20 \%$ EA in TMP saturated with & \\
& & $20 \% \mathrm{H}_{2} \mathrm{O}$ in EG & - \\
0 & $3 \cdot 5$ & $20 \%$ EA in TMP & Progesterone \\
1 & $3 \cdot 5$ & $30 \%$ EA in TMP & Corticosterone \\
2 & $5 \cdot 0$ & $40 \%$ EA in TMP & Cortisol \\
3 & $6 \cdot 0$ & $50 \%$ EA in TMP & Aldosterone \\
\hline
\end{tabular}

*EA = ethyl acetate; TMP = trimethyl pentane; EG = ethylene glycol.

Steroid pellet implantation and embryo collection. Aldosterone-containing or placebo pellets (Innovative Res. of America, Rockville, MD) were implanted subcutaneously in virgin female New Zealand White rabbits $1-2$ days before mating. The final steroid dose was $4.32 \mathrm{mg} / \mathrm{kg}$ body weight. The rabbits were naturally mated to 2 bucks on Day 0. Blood was collected by ear venesection from some animals on Days 0, 2, 4 and 6 p.c. and the aldosterone was assayed to verify high or normal values. Aldosterone concentrations in treatment rabbits were elevated by Day $0 p . c$. and remained elevated for the course of the experiment. On Day 6 or 7 p.c. blood samples were collected and the rabbits killed with an intravenous overdose of T-61 Euthanasia solution (N-[2-(m-methoxy-phenyl)-2-ethyl-butyl-(1)]gamma-hydroxybutyramide, 4,4'-methylene-bis(cyclohexyl-trimethyl-ammonium iodide, tetracaine hydrochloride; Amer. Hoechst Co., Somerville, NJ). The uterine horns were excised and placed in $37^{\circ} \mathrm{C}$ modified F10 medium (Medium mF10) consisting of Ham’s F10 medium (GIBCO, Grand Island, NY) buffered with 20 mM-Hepes (N-2hydroxyethylpiperazine- $N^{\prime}$-2-ethanesulphonic acid) and adjusted to $\mathrm{pH} 7 \cdot 4$. For collection of Day 6 p.c. embryos both horns were flushed with medium $\mathrm{mF10}$. Day 7 p.c. embryos were dissected out of the uterus into medium $\mathrm{mF} 10$.

Measurement of sodium fluxes. The rate of unidirectional transepithelial ${ }^{22} \mathrm{Na}^{+}$influx was measured using the method of Benos (1981). Briefly, embryos were incubated at $37^{\circ} \mathrm{C}$ in $0.5 \mathrm{ml} \mathrm{Krebs-Ringer} \mathrm{bicarbonate} \mathrm{with} \mathrm{glucose}$ (KRBG) containing $4 \mu \mathrm{Ci}^{22} \mathrm{Na}^{+}$with or without $1 \mathrm{~mm}$-amiloride (Sigma) for $10 \mathrm{~min}$ (Day 7 p.c.) or $20 \mathrm{~min}$ (Day 6 p.c.). The composition of the $\mathrm{KRBG}$ was (in $\mathrm{mM}$ ): $\mathrm{NaCl}, 119 ; \mathrm{KCl}, 4 \cdot 74 ; \mathrm{CaCl}_{2}, 1 \cdot 71 ; \mathrm{KH}_{2} \mathrm{PO}_{4}, 1 \cdot 19$; $\mathrm{MgSO}_{4} \cdot 7 \mathrm{H}_{2} \mathrm{O}, 1 \cdot 19 ; \mathrm{NaHCO}_{3}, 2 \cdot 5$; and glucose, 5.55. Blastocoele fluid was collected by micropuncture and samples

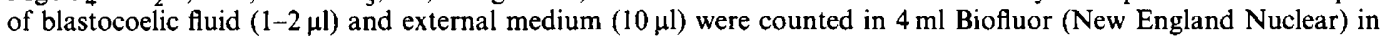
a Beckman LS 6800 liquid scintillation spectrometer. Sodium influx for each blastocyst was calculated from the following equation:

$$
j_{\mathrm{Na}}=\mathrm{C} /\left[\mathrm{A} \cdot \Delta t\left(\mathrm{~S}_{\mathrm{o}}-\mathrm{S}_{\mathrm{i}}^{0.5 t}\right)\right]
$$

where $J_{\mathrm{Na}}^{i}$ represents the total unidirectional $\mathrm{Na}^{+}$influx $\left(\mu \mathrm{mol} \mathrm{Na} \mathrm{Na}^{+} \cdot \mathrm{cm}^{-2} \cdot \mathrm{h}^{-1}\right), \mathrm{C}$ the total radioactivity in the blastocoele fluid (c.p.m.), A the surface area $\left(\mathrm{cm}^{2}\right), \Delta t$ the duration of the flux period (h), $\mathrm{S}_{0}$ the specific activity of $\mathrm{Na}^{+}$in the external bathing medium (c.p.m./ $\mu$ mol Na${ }^{+}$), and $\mathrm{S}_{\mathrm{i}}{ }^{0-5 t}$ the specific activity of $\mathrm{Na}^{+}$in the blastocoele fluid (c.p.m. $/ \mu \mathrm{mol} \mathrm{Na}{ }^{+}$) at the midpoint of the flux period. Transepithelial $\mathrm{Na}^{+}$influx is linear for at least $30 \mathrm{~min}$ in Day 6 embryos (Benos \& Biggers, 1983).

For the efflux experiments, ${ }^{22} \mathrm{Na}^{+}\left(9 \times 10^{5}\right.$ d.p.m. $)$ and $\left[{ }^{3} \mathrm{H}\right]$ polyethylene glycol $\left(\left[{ }^{3} \mathrm{H}\right] \mathrm{PEG} ; 1 \times 10^{4} \mathrm{~d} . \mathrm{p} . \mathrm{m}.\right)$ in $2 \mu \mathrm{l}$ distilled water were injected into each blastocoele. Each blastocyst was placed in a chamber which was constantly perfused with $\mathrm{KRBG}$ at $37^{\circ} \mathrm{C}$ with or without $1 \mathrm{~mm}$-amiloride. Flow rate through the chamber was adjusted such that $98-99 \%$ of $9 \times 10^{5}$ d.p.m. ${ }^{22} \mathrm{Na}^{+}$was cleared from the chamber in $1 \mathrm{~min}$. This flow rate ensured near background levels of ${ }^{22} \mathrm{Na}^{+}$in the chamber at any given instant during an experiment, thereby preventing significant backflux of ${ }^{22} \mathrm{Na}^{+}$into the blastocoele. One scintillation vial was used to collect the chamber effluence during 1-2 min and a series of 3-15 vials were collected for each blastocyst. At the end of the efflux period, a sample of blastocoele fluid was taken by micropuncture. Blastocysts incubated for up to $30 \mathrm{~min}$ in $\mathrm{KRBG}$ and [ ${ }^{3} \mathrm{H}$ ]PEG had no detectable radioactivity in the blastocoele fluid. Therefore, it was assumed that under the conditions of the efflux experiment the intact trophectoderm was impermeable to $\left[{ }^{3} \mathrm{H}\right] \mathrm{PEG}$. Based on this assumption, external ${ }^{22} \mathrm{Na}^{+}$was measured only when $\left[{ }^{3} \mathrm{H}\right] \mathrm{PEG}$ was undetectable in the external medium, to ensure that the membrane had resealed around the injection site before the $\mathrm{Na}^{+}$efflux rate was calculated according to the following equation:

$$
J_{\mathrm{Na}}^{\mathrm{i}}=\mathrm{C} /\left(\mathrm{A} \cdot \Delta t \cdot \mathrm{S}_{\mathrm{i}}\right)
$$

where $J_{\mathrm{Na}}^{\mathrm{i}}$ represents the unidirectional $\mathrm{Na}^{+}$efflux $\left(\mu \mathrm{mol} \mathrm{Na}{ }^{+} \cdot \mathrm{cm}^{-2} \cdot \mathrm{h}^{-1}\right), \mathrm{C}$ the total radioactivity in the external medium (d.p.m.), A the surface area $\left(\mathrm{cm}^{2}\right), \Delta t$ the duration of effluent collection (h), and $\mathrm{S}_{\mathrm{i}}$ the specific activity of $\mathrm{Na}^{+}$ in the blastocoele (d.p.m./ $\mu \mathrm{mol} \mathrm{Na}{ }^{+}$).

Statistics. The Fisher-Behrens test for the comparison of two population means with unequal variances was used to evaluate differences between mean hormone concentrations from pseudopregnant and pregnant rabbits on the 
same day p.c. and to compare treatment and control hormone concentrations. Student's $t$ test was used for the evaluation of the amiloride sensitivity of the $\mathrm{Na}^{+}$influx rates and for the comparisons of amiloride-insensitive $\mathrm{Na}^{+}$ influx and efflux rates.

\section{Results}

\section{Maternal endocrine profile}

Maternal blood samples were obtained via surgically implanted venous catheters to determine whether there are sustained increases in circulating concentrations of adrenal steroids during the first week of pseudopregnancy and pregnancy. Blood samples for measurement of progesterone, aldosterone, corticosterone and cortisol concentrations were collected hourly between 09:30 and 14:30 h from unstressed non-pregnant female rabbits. There were no differences suggestive of circadian variations between hormone concentrations during this short sampling period. This was also true when the rabbits were pseudopregnant or pregnant. Mean plasma hormone concentrations ( \pm s.d. of total sample population) in 9 unstressed, non-pregnant female rabbits were $146 \cdot 1 \pm 92 \cdot 0 \mathrm{pg}$ progesterone $/ \mathrm{ml}, 24.4 \pm 23 \cdot 1 \mathrm{pg}$ aldosterone $/ \mathrm{ml}, 5 \cdot 6 \pm 5.4 \mathrm{ng}$ corticosterone $/ \mathrm{ml}$, and $2 \cdot 6 \pm 3 \cdot 0 \mathrm{ng}$ cortisol $/ \mathrm{ml}$.

\section{Progesterone}

In non-pregnant control females, progesterone concentrations were $<250 \mathrm{pg} / \mathrm{ml}$. Pseudopregnant and pregnant animals had significantly higher progesterone concentrations as shown in Figs 1 and 2. This permitted confirmation of ovulation. Pregnancy was also confirmed on Day 7 by the presence of embryos in the uterine horns. A pronounced surge of progesterone was seen within 30 min after mating or hCG injection. By Day 1 p.c., progesterone had fallen to control values, then gradually increased over the period of observation. There were no statistically significant differences $(P>0.05)$ between circulating progesterone concentrations in pseudopregnant and pregnant rabbits on any given day.

\section{Adrenal steroids}

Blood samples obtained on the day before mating or hCG injection allowed each rabbit to serve as its own control. The absolute mean adrenal hormone concentrations varied greatly between rabbits. Since this inter-rabbit variation might have obscured real trends and differences between pseudopregnant and pregnant rabbits, mean plasma steroid concentrations for each rabbit on each day were divided by the mean value of the control, i.e. Day -1 , for that same rabbit to provide normalized adrenal hormone values. The normalized means for each day were then averaged and plotted as 'composite profiles' (Fig. 3).

\section{Aldosterone}

There were no statistically significant differences $(P>0.05)$ between plasma aldosterone concentrations in pseudopregnant and pregnant rabbits on any given day. There were no sustained changes from control $(P>0.05)$ in aldosterone concentrations.

\section{Corticosterone and cortisol}

There were no statistically significant differences $(P>0.05)$ between circulating corticosterone concentrations in pregnant and pseudopregnant rabbits on any given day during the observation period. Plasma corticosterone was marginally depressed $(P>0.05)$ in Day 5 p.c. rabbits. All other 


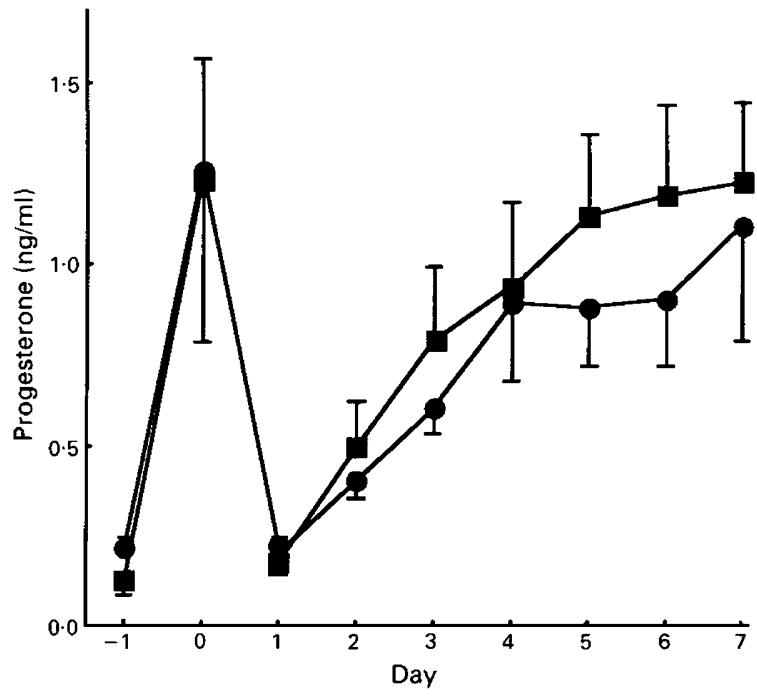

Fig. 1. Plasma progesterone concentrations in 5 pseudopregnant $(\mathbf{\square})$ and 6 pregnant $(\boldsymbol{O})$ rabbits. The rabbits were mated or injected with $25 \mathrm{i} . \mathrm{u}$. hCG at 10:00 h on Day 0. For each rabbit, 2-3 samples per day were averaged. These means were then averaged for all rabbits on each day to give the s.e.m. shown.

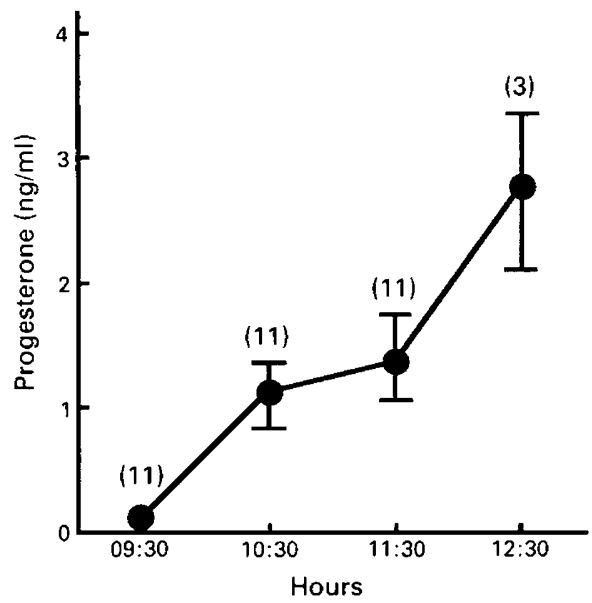

Fig. 2. Progesterone secretion in female rabbits in response to mating or hCG at 10:00 h. Calculations were performed as in Fig. 1. Values are mean \pm s.e.m. for the number of rabbits in parentheses.

corticosterone measurements were not significantly different $(P>0.05)$ from control values. There were no statistically significant differences $(P>0.05)$ between circulating cortisol concentrations in pseudopregnant and pregnant rabbits on any given day. There was no elevation from control $(P>0.05)$ in cortisol concentrations, although pregnant cortisol concentrations were significantly lower than control on Days $1,2,3,5$ and 7 p.c. $(P \leqslant 0.05)$. This was probably an artefact caused by the fact that some rabbits were not as used to handling on Day -1 as they were later in the experiment. A comparison of the absolute mean adrenal steroid concentrations in pseudopregnant and pregnant rabbits is shown in Table 2. 

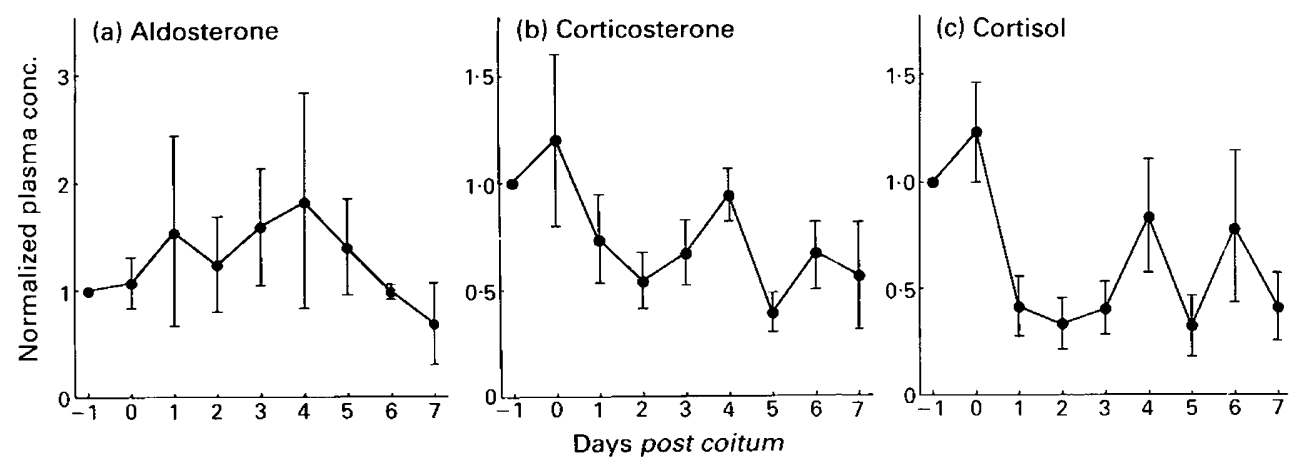

Fig. 3. Composite graph of normalized plasma aldosterone (a), corticosterone (b), and cortisol (c) concentrations for 6 pregnant rabbits. Values are mean \pm s.e.m. The mean steroid concentrations on Day -1 were $33.8 \pm 10.2 \mathrm{pg}$ aldosterone $/ \mathrm{ml}, 5.5 \pm 1.0 \mathrm{ng} \operatorname{cortisol} / \mathrm{ml}$, and $3 \cdot 2 \pm 1 \cdot 2 \mathrm{ng}$ corticosterone $/ \mathrm{ml}$.

Table 2. Circulating adrenal concentrations in female rabbits

\begin{tabular}{ccc}
\hline & Pregnant & Pseudopregnant \\
\hline Aldosterone $(\mathrm{pg} / \mathrm{ml})$ & $18.9 \pm 12 \cdot 6(132)$ & $23 \cdot 8 \pm 8.9(92)$ \\
Corticosterone $(\mathrm{ng} / \mathrm{ml})$ & $3.5 \pm 0.9(132)$ & $4.1 \pm 2 \cdot 1(109)$ \\
Cortisol $(\mathrm{ng} / \mathrm{ml})$ & $1 \cdot 7 \pm 0.6(132)$ & $1.6 \pm 0.7(109)$ \\
\hline
\end{tabular}

Adrenal steroid hormones were measured in 5 pseudopregnant and 6 pregnant rabbits: $2-3$ samples for each day were averaged for each rabbit to yield 1 hormone value/day/rabbit for each steroid. Then these values were averaged for all rabbits each day. Finally, the average concentration of \pm s.d. of each hormone was calculated for the first 8 days after mating or hCG. The number of individual determinations is given in parentheses.

\section{Effect of aldosterone in vivo on blastocyst sodium transport in vitro}

To determine whether sustained, high levels of aldosterone in vivo can induce amiloride-sensitive $\mathrm{Na}^{+}$transport into blastocysts, timed-release aldosterone-containing or placebo pellets were implanted subcutaneously in female rabbits. Plasma aldosterone concentrations in the treatment group were at least 5 -fold higher than in the control group. After recovery from surgery, the rabbits were mated and the embryos collected on Days 6 or 7 p.c. Sodium influx rates were measured on these embryos in the presence or absence of $1 \mathrm{~mm}$-amiloride. Sustained elevation of aldosterone concentrations in vivo did not increase basal $\mathrm{Na}^{+}$influx in rabbit blastocysts nor did it increase the percentage-inhibition of $\mathrm{Na}^{+}$influx by amiloride (Table 3).

\section{Sodium efflux}

The rate of $\mathrm{Na}^{+}$efflux from the blastocoele was measured to determine whether the amiloridesensitive component of $\mathrm{Na}^{+}$influx is needed for blastocyst expansion. To illustrate this proposal:

$\mathrm{N}_{1}=$ amiloride-refractory $\mathrm{Na}^{+}$influx

$\mathrm{A}=$ amiloride-sensitive $\mathrm{Na}^{+}$influx

$\mathrm{N}_{1}+\mathrm{A}=$ driving force for fluid movement into blastocoele

$\mathrm{N}_{2}=$ driving force for fluid movement out of blastocoele $=\mathrm{Na}^{+}$efflux

If $\mathrm{N}_{2}$ is amiloride-refractory and $\mathrm{N}_{2}=\mathrm{N}_{1}$, then blastocyst swelling is due to $A$. 
Table 3. Effect of elevated aldosterone concentrations on embryonic sodium transport

\begin{tabular}{cccccc}
\hline \multirow{2}{*}{$\begin{array}{c}\text { Day } \\
p . c .\end{array}$} & $\begin{array}{c}\text { Pellet } \\
\text { type }\end{array}$ & $\begin{array}{c}\text { Aldosterone } \\
(\mathrm{pg} / \mathrm{ml})\end{array}$ & \multicolumn{2}{c}{$\mathrm{Na}^{+}$influx $\left(\mu \mathrm{mol} \mathrm{Na}^{+} \mathrm{cm}^{-2} \mathrm{~h}^{-1}\right)$} & \\
\cline { 4 - 5 } & $\mathrm{P}$ & $118 \pm 9$ & Control & 1 mM-amiloride & \% Inhibition \\
\hline 7 & $(4)$ & $0.40 \pm 0.03$ & $0.37 \pm 0.03$ & 7.8 \\
7 & $\mathrm{~A}$ & $745 \pm 127$ & $0.43 \pm 0.04$ & $0.35 \pm 0.04$ & 18.1 \\
6 & $(4)$ & $132 \pm 14$ & $0.51 \pm 0.03$ & $0.45 \pm 0.03$ & 13.3 \\
6 & $\mathrm{P}$ & $(6)$ & $(28)$ & $(28)$ & 19.1 \\
6 & $\mathrm{~A}$ & $3017 \pm 1624$ & $0.43 \pm 0.04$ & $0.34 \pm 0.04$ & $(8)$ \\
\hline
\end{tabular}

Sodium influx for each embryo was measured as described in 'Materials \& Methods'. Values are mean \pm s.e.m.

Sodium efflux rates were $0.22 \pm 0.03 \mu \mathrm{mol} \mathrm{Na}{ }^{+} . \mathrm{cm}^{-2} \cdot \mathrm{h}^{-1}$ for 8 Day-6 embryos and $0.29 \pm$ $0.03 \mu \mathrm{mol} \mathrm{Na}{ }^{+} . \mathrm{cm}^{-2} \cdot \mathrm{h}^{-1}$ for 14 Day-7 embryos. Amiloride (1 mM) had no effect on these efflux rates $(P>0 \cdot 05)$. A comparison was made between amiloride-refractory $\mathrm{Na}^{+}$efflux and amiloriderefractory $\mathrm{Na}^{+}$influx (Table 3, column 5). Sodium efflux from Day-6 embryos was significantly less $(P \leqslant 0.05)$ than $\mathrm{Na}^{+}$influx. There was no significant difference $(P>0.05)$ between amiloriderefractory $\mathrm{Na}^{+}$influx and efflux for Day-7 embryos.

\section{Discussion}

Before this study few data existed on the adrenal endocrinology of the pregnant rabbit. To test the hypothesis that a sustained mineralocorticoid increase induces a change in the amiloride-sensitivity of the rabbit blastocyst, it was necessary to determine physiological concentrations of circulating adrenal steroids. Aldosterone is the primary activator of amiloride-sensitive conductive $\mathrm{Na}^{+}$transport in many epithelia. Aldosterone was therefore the most likely regulator of an amiloride-sensitive conductive $\mathrm{Na}^{+}$pathway. Corticosterone was measured, because it functions as a mineralocorticoid in some systems, albeit a less potent one than aldosterone (Anderson \& Fanestil, 1978). Cortisol served as a control for the catheter technique because cortisol increases rapidly in stressed animals. Progesterone served as an indicator of reproductive status, since progesterone concentrations rise dramatically during pseudopregnancy or pregnancy (Challis et al., 1973; Mills \& Gerardot, 1984). Rabbits which did not have elevated progesterone values after mating or hCG injection were excluded from the study.

Our measurements of adrenal steroid concentrations in catheterized female rabbits correspond well with those of Grospietsch et al. (1980) who reported values of $78 \pm 101 \mathrm{pg}$ aldosterone/ml ( \pm s.d.) and $7.4 \pm 7.4 \mathrm{ng}$ glucocorticosteroid $/ \mathrm{ml}(83 \%<10 \mathrm{ng} / \mathrm{ml})$ in catheterized male rabbits. The frequency of their sampling procedure (every $20 \mathrm{~min}$ ) may have interfered with the normal drinking/excretion patterns of the rabbits, thereby artificially increasing the aldosterone concentrations. Ganjam et al. (1972) reported values of $4 \cdot 3 \pm 1 \cdot 1 \mathrm{ng}$ corticosterone/ml ( $\pm \mathrm{s} . \mathrm{d}$.) and $1.0 \pm 0.3 \mathrm{ng}$ cortisol $/ \mathrm{ml}$ in non-pregnant female rabbits decapitated within $30 \mathrm{sec}$ after first handling. Our results confirm these reports concerning the low secretory rate of the unstressed rabbit adrenal gland.

A non-stressful method of blood collection, such as the indwelling catheter technique, is essential for measurement of physiological adrenal hormone concentrations. Guleff \& Beck (1981) reported corticosterone values for pregnant rabbits of $24 \mathrm{ng} / \mathrm{ml}$ (Day 0 ) and $28 \mathrm{ng} / \mathrm{ml}$ (Day 7), while cortisol remained at $11 \mathrm{ng} / \mathrm{ml}$. In another study, using non-pregnant rabbits, corticosterone was 


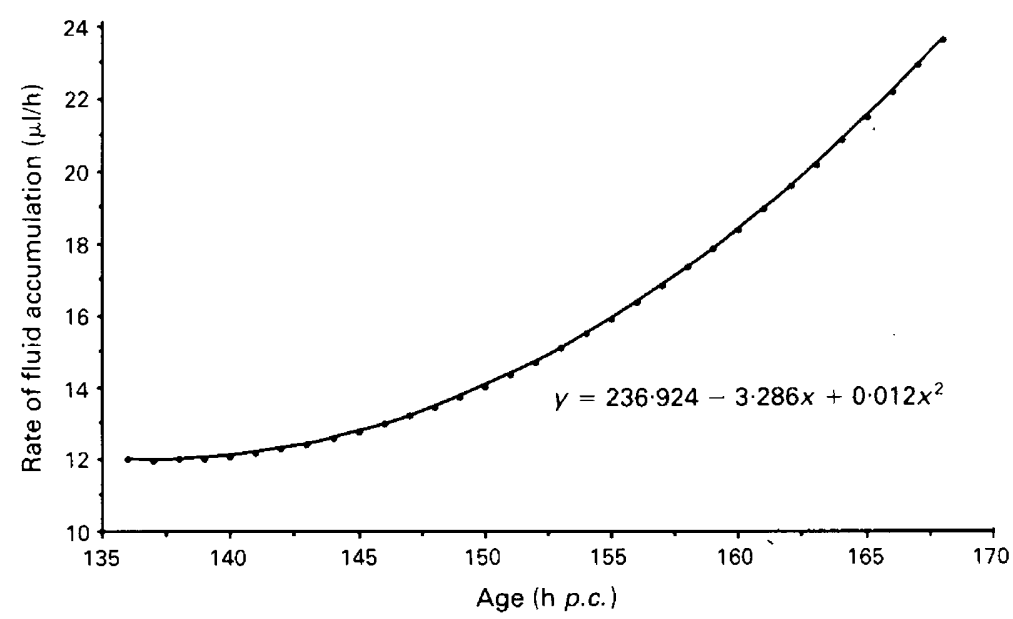

Fig. 4. Rate of blastocoele fluid accumulation. The rate of volume increase was calculated for 941 embryos from the first derivative of the best-fitting polynomial regression equation describing the change in blastocyst volume between 136 and $164 \mathrm{~h}$ p.c.

$24 \mathrm{ng} / \mathrm{ml}$, while cortisol was $3 \mathrm{ng} / \mathrm{ml}$ (Mulay et al., 1973). Both studies used venesection to collect blood samples. These hormone concentrations are 6-7 times higher than the physiological levels reported here. A comparison of hormone values from blood collected via catheters (Table 2) and by venesection (Table 3 ) shows that aldosterone also rises dramatically under stress.

Progesterone concentrations in this study were 8-fold higher than control concentrations by 30 min after mating or hCG injection. This agrees well with the almost 7 -fold increase found by Fuchs \& Beling (1974) although the absolute concentrations of all their progesterone measurements were higher, probably due to methodological differences. Mills \& Gerardot (1984) reported an acute progesterone rise by $2 \mathrm{~h}$ p.c. It appears likely that the sources of this preovulatory progesterone are the large ovarian follicles of the ovary, since Osteen \& Mills (1980) reported a mean preovulatory progesterone content of $1.03 \mathrm{ng}$ per follicle.

Several species exhibit developmental changes in the ability of amiloride to inhibit $\mathrm{Na}^{+}$transport across epithelia. Pig colon first exhibits amiloride sensitivity on the day after birth and this sensitivity continues to increase for the next 8 days (Cremaschi et al., 1979, 1981; Ferguson et al., 1979; Hills et al., 1980). This event is triggered by sustained, high concentrations of plasma aldosterone for at least a week after birth. Aldosterone can also induce amiloride-sensitivity in adult colon from rat (Will et al., 1980, 1985; Perrone et al., 1984; Perrone \& Jenks, 1984), rabbit (Frizzell \& Schultz, 1978; Clauss et al., 1985), and chicken (Clauss et al., 1984). For example, adult rat colon is normally insensitive to amiloride. However, amiloride-sensitive $\mathrm{Na}^{+}$transport can be induced by giving aldosterone or by diet changes which elevate plasma aldosterone (Will et al., 1980, 1985; Perrone et al., 1984; Perrone \& Jenks, 1984). It takes about 4 days of continuously high mineralocorticoids for the maximum change in amiloride sensitivity. Spironolactone, an aldosterone antagonist, blocks the response. Progesterone, oestradiol-17 $\beta$ or testosterone have no effect on $\mathrm{Na}^{+}$ transport (Will et al., 1985).

Comparison of adrenal hormones in pseudopregnant and pregnant rabbits allowed us to distinguish between hormonal changes due solely to ovulation and high progesterone, and hormonal changes due to embryos in the uterus. The reproductive status of the female rabbit had no apparent effect on adrenal hormone concentrations. Therefore, ovulation and high progesterone concentrations by themselves did not affect plasma adrenal steroids. In addition, there were no pregnancyspecific changes during preimplantation embryonic development. It seems unlikely, therefore, that 
a sustained increase in adrenal steroid concentrations is needed for the development of amiloride sensitivity in this system.

Formation of the blastocoelic fluid involves active transport of electrolytes, notably $\mathrm{Na}^{+}$, across the trophectoderm, with water following passively (Gamow \& Daniel, 1970; Cross, 1973; Borland et al., 1976, 1977; Powers et al., 1977; Biggers et al., 1978). It was possible that an important fluctuation in adrenal steroids could be missed if it occurred during the night. To circumvent this problem, aldosterone concentrations in vivo were artificially elevated during the first week of pregnancy and then the effects on embryonic $\mathrm{Na}^{+}$transport were measured in vitro. This protocol mimicked the experiments with neonatal pig and adult rat colonic material. Elevation of aldosterone concentrations in vivo did not increase either basal $\mathrm{Na}^{+}$influx or the percentage of amiloride-sensitive $\mathrm{Na}^{+}$flux into rabbit embryos (Table 3). The rabbit trophectoderm does not behave in the same manner as do other aldosterone-responsive epithelia.

The results of this and previous studies indicate that a change in the mechanisms of $\mathrm{Na}^{+}$flux across the trophectoderm occurs just before implantation. Day- 6 embryos do not appear to need amiloride-sensitive $\mathrm{Na}^{+}$influx for blastocyst expansion. By Day 7 p.c. $\mathrm{Na}^{+}$efflux was equivalent in magnitude to the component of $\mathrm{Na}^{+}$influx not inhibited by amiloride. Sometime between Days 6 and 7 the amiloride-sensitive component of $\mathrm{Na}^{+}$influx seems to become necessary for net fluid accumulation in the blastocoele. As seen in Fig. 4, the rate of blastocyst fluid accumulation begins to increase rapidly after Day $6(144$ h p.c.) at the same time that the trophectoderm acquires amiloridesensitivity. The rate of blastocyst expansion continues to rise until at least the time of implantation, as do the amiloride-sensitive membrane potential and $\mathrm{Na}^{+}$influx. This behaviour is consistent with our hypothesis.

Three investigations have studied the development of amiloride sensitivity across the rabbit trophectoderm (Powers et al., 1977; Benos, 1981; Benos \& Biggers, 1983). In all 3 studies, embryos were exposed to fetal calf serum (FCS) before measurement of amiloride sensitivity. In the present study, embryos were never exposed to FCS in vitro and did not exhibit amiloride-sensitive $\mathrm{Na}^{+}$ transport. Their $\mathrm{Na}^{+}$influx rates correspond well with published rates for embryos which were not sensitive to amiloride. Powers et al. (1977) found that Day-6.5 embryos had a transtrophectodermal potential difference of $+4.5 \mathrm{mV}$ in Medium mF10 with FCS, but a potential difference of only $+6.0 \mathrm{mV}$ in KRBG, suggesting stimulation of transport functions by some factor in the enriched medium, probably a component in the serum.

We thank R. Todd, W. Paginelli, P. Ellison and C. Worthman for help with this study; Ms Karine Begg for valuable technical assistance during the surgical procedures; and Dr R. H. Underwood for the generous gift of aldosterone antibody. The animals used in this study were maintained in accordance with the guidelines of the Committee on Animals of Harvard Medical School and with those prepared by the Committee on Care and Use of Lab. Animals of the Institute of Lab. Animal Resources, Natl. Res. Council (DHEW publication No. (NIH) 78-23, revised 1978). All radioimmunoassays were performed in the RIA core facility of the LHRRB which was funded by NIH Center Grant P30 HD06645. This work was supported by NIH Grants HD 12353, AM25886, HD21302, by funds from the Andrew W. Mellon Foundation, and by funds from EM Tek Corporation. LLN was supported by NIH Training Grants T32GM07258 and T32HD07130.

\section{References}

Anderson, N.S. \& Fanestil, D.D. (1978) Biology of mineralocorticoid receptors, In Receptors and Hormone Action, pp. 323-351. Eds B. W. O'Malley \& L. Birnbaumer. Academic Press, New York.

Benos, D.J. (1981) Ouabain binding to preimplantation rabbit blastocysts. Devl. Biol. 83, 69-78.

Benos, D.J. \& Biggers, J.D. (1983) Sodium and chloride co-transport by preimplantation rabbit blastocysts. J. Physiol., Lond. 342, 23-33.

Biggers, J.D., Borland, R.M. \& Lechene, C.P. (1978) Ouabain-sensitive fluid accumulation and ion transport by rabbit blastocysts. J. Physiol., Lond. 280, 319-330.

Borland, R.M., Biggers, J.D. \& Lechene, C.P. (1976) 
Kinetic aspects of rabbit blastocele fluid accumulation: an application of electron probe microanalysis. Devl Biol. 50, 201-211.

Borland, R.M., Biggers, J.D. \& Lechene, C.P. (1977) Fluid transport by rabbit preimplantation blastocysts in vitro. J. Reprod., Fert. 51, 131-135.

Bridges, R.J., Rummel, W. \& Schreiner, J.S. (1987) In vitro effects of dexamethasone on sodium transport across rat colon. J. Physiol., Lond. 383, 69-77.

Challis, J.R.G., Davies, I.J. \& Ryan, K.J. (1973) The concentration of progesterone, estrone, and estradiol$17 \beta$ in the plasma of pregnant rabbit. Endocrinology 93, $971-976$.

Clauss, E., Arnason, S.S., Munck, B.G. \& Skadhauge, E. (1984) Aldosterone-induced sodium transport in lower intestine: effects of varying $\mathrm{NaCl}$ intake. Pflügers Arch. 401, 354-360.

Clauss, E., Dürr, J., Skadhauge, E. \& Hörnicke, H. (1985) Effects of aldosterone and dexamethasone on apical membrane properties and Na-transport of rabbit distal colon in vitro. Pfiugers Arch. 403, $186-192$.

Crabbe, J. (1964) Stimulation by aldosterone of active sodium transport across the isolated ventral skin of amphibia. Endocrinology 75, 809-811.

Cremaschi, D., Ferguson, D.R., Henin, S., James, P.S., Meyer, G. \& Smith, M.W. (1979) Post-natal development of amiloride sensitive sodium transport in pig distal colon. J. Physiol., Lond. 292, 481-494.

Cremaschi, D., James, P.S., Meyer, G. \& Smith, M.W. (1981) Electrophysiology of pig distal colon measured during early post-natal development. $J$. Physiol., Lond. 314, 137-149.

Cross, M.H. (1973) Active sodium and chloride transport across the rabbit blastocoele wall. Biol. Reprod. 8, 566-575.

Daniel, J.C. (1964) Early growth of rabbit trophoblast. Am. Nat. 98, 85-98.

Ferguson, D.R., James, P.S., Paterson, J.Y.F., Saunders, J.C. \& Smith, M.W. (1979) Aldosterone induced changes in colonic sodium transport occurring naturally during development in neonatal pig. $J$. Physiol., Lond. 292, 495-504.

Frizzell, R.A. \& Schultz, S.G. (1978) Effect of aldosterone on ion transport by rabbit colon in vitro. J. Membr. Biol. 39, 1-26.

Fuchs, A.-R. \& Beling, C. (1974) Evidence for early ovarian recognition of blastocyst in rabbit. Endocrinology 95, $1054-1058$.

Gamow, E. \& Daniel, J.C. (1970) Fluid transport in the rabbit blastocyst. Wilhelm Roux Arch. EntwMech. Org. 164, 261-278.

Ganjam, V.K., Campbell, A.L. \& Murphy, B.E.P. (1972) Changing patterns of circulating corticosteroids in rabbits following prolonged treatment with ACTH. Endocrinology 91, 607-611.

Gibori, G., Antczak, E. \& Rothchild, I. (1977) The role of estrogen in the regulation of luteal progesterone secretion in the rat after day 12 of pregnancy. Endocrinology 100, 1483-1495.

Grospietsch, G., Finske, M. \& Konig, A. (1980) Basal plasma aldosterone levels and tetracosactid-induced increase of aldosterone secretion in conscious male rabbits: lack of correlation with glucocorticosteroid levels. Endokrinologie 75, 324-334.
Guleff, P.S. \& Beck, R.R. (1981) Maternal and fetal adrenocortical function in the diabetic rabbit. $A m$. J. Physiol. 240, (Endocrinol. Metab. 3), E217-E225.

Hills, F., James, P.S., Paterson, J.Y.F. \& Smith, M.W. (1980) Delayed development of amiloride-sensitive sodium transport in lamb distal colon. J. Physiol., Lond. 303, 371-384.

MacKnight, A.D.C., DiBona, D.R. \& Leaf, A. (1980) Sodium transport across toad urinary bladder: a model 'tight' epithelium. Physiol. Rev. 60, 615-715.

Manlimos, F.S. \& Abraham, G.E. (1975) Chromatographic purification of tritiated steroids prior to use in radioimmunoassay. Analyt. Letters 8, 403-410.

Mills, T.M. \& Gerardot, R.J. (1984) Dissociation of copulation from ovulation in pregnant rabbits. Biol. Reprod. 30, 1243-1252.

Mulay, S., Giannopoulos, G. \& Solomon, S. (1973) Corticosteroid levels in the mother and fetus of the rabbit during gestation. Endocrinology 93, 1342-1348.

Nielsen, L.L. (1986) Characterization of amiloridesensitive sodium transport in preimplantation rabbit blastocysts. Ph.D. thesis, Harvard University, Cambridge, MA

Osteen, K.G. \& Mills, T.M. (1980) Changes in the size, distribution, and steroid content of rabbit ovarian follicles during early pseudopregnancy. Biol. Reprod. 22, $1040-1046$.

Palmer, L.G. \& Edelman, I.S. (1981) Control of apical sodium permeability in the toad urinary bladder by aldosterone. Ann. N.Y. Acad. Sci. 372, 1-14.

Perrone, R.D. \& Jenks, S.L. (1984) Suppression of coupled $\mathrm{Na}-\mathrm{Cl}$ absorption by aldosterone and dexamethasone in rat distal colon in vitro. Am. J. Physiol. 246, (Renal Fluid Electrolyte Physiol. 15), F785-F793.

Perrone, R.D., Alexander, E.A., Bengele, H.H. \& Schwartz, J.H. (1984) Effect of aldosterone and dexamethasone pretreatment on sodium transport in rat distal colon in vitro. Pfiügers Arch. 400, 257-261.

Powers, R.D., Horland, R.M. \& Biggers, J.D. (1977) Amiloride-sensitive rheogenic $\mathrm{Na}^{+}$transport in rabbit blastocyst. Nature, Lond. 270, 603-604.

Rodbard, D. \& Rodgers, R.C. (1976) The kinetics of radioligand assay. In Hormones in Human Blood Detection and Assay, pp. 92-114. Ed. H. N. Antoniades. Harvard University Press, Cambridge.

Underwood, R.H. \& Williams, G.H. (1972) The simultaneous measurement of aldosterone, cortisol, and corticosterone in human peripheral plasma by displacement analysis. J. Lab. Clin. Med. 79, 848-862.

Will, P.C., Lebowitz, J.L. \& Hopfer, U. (1980) Induction of amiloride-sensitive sodium transport in the rat colon by mineralocorticoids. Am. J. Physiol. 238, (Renal Fluid Electrolyte Physiol, 7), F261-F268.

Will, P.C., Cortright, R.N., Deligle, R.C., Douglas, J.G. \& Hopfer, U. (1985) Regulation of amiloride-sensitive electrogenic sodium transport in the rat colon by steroid hormones. Am. J. Physiol. 248, (Gastrointest, Liver Physiol, 11), G124-Gi32. 